\title{
Evaluating earthquake disaster risk management in schools in Rungwe Volcanic Province in Tanzania
}

\author{
Author: \\ Evaristo Haulle \\ Affiliation: \\ ${ }^{1}$ Geography Department, \\ Mkwawa University College \\ of Education, University of \\ Dar es Salaam, Tanzania \\ Correspondence to: \\ Evaristo Haulle \\ Email: \\ evarist@udsm.ac.tz \\ Postal address: \\ PO Box 2284, Iringa, Tanzania \\ Dates: \\ Received: June 2011 \\ Accepted: 20 Apr. 2012 \\ Published: 20 June 2012 \\ How to cite this article: \\ Haulle, E., 2012, 'Evaluating \\ earthquake disaster risk \\ management in schools in \\ Rungwe Volcanic Province \\ in Tanzania', Jàmbá: Journal \\ of Disaster Risk Studies 4(1), \\ Art. \#44, 7 pages. http:// \\ dx.doi.org/10.4102/jamba. \\ v4i1.44
}

C 2012. The Authors. Licensee: AOSIS OpenJournals. This work is licensed under the Creative Commons Attribution License.
This article establishes existing knowledge on earthquakes and coping mechanisms employed in reducing the severity of adverse impacts caused by an earthquake disaster in a specific locality. The purpose of the study was to recommend useful measures for disaster risk management. It also more particularly aimed at assessing mechanisms employed in reducing the disaster risk and integrating knowledge of disasters and hazards in primary and secondary school curricula. The study was carried out in Rungwe Volcanic Province in Rungwe District, Tanzania, and included recording people's attitudes towards earthquake disaster and locations of schools. It employed focus group discussions, public hearings and interviews in order to capture the actual situation relating to risk and vulnerability assessments by the community. The study revealed high levels of risk and vulnerability to the impact of earthquakes on the part of the community, who accepted earthquakes as a normal phenomenon and therefore did not employ special measures to reduce the impact. The study showed that the community's coping mechanisms and the extent to which disaster management knowledge has been integrated in school curricula are inadequate in addressing earthquake disasters. It is thus recommended that traditional and modern technologies be integrated in curricula and later in sustainable practices; such technologies include the belief in 'Nyifwila', traditional housing style and wooden housing, and non-structural planning for disaster risk management.

\section{Introduction}

The Great East Africa Rift Valley System in general and Rungwe Volcanic Province (RVP) in particular have frequently experienced earthquakes that claim human lives, properties and environmental resources. For example, the 1955 quake that mostly destroyed public offices in Tukuyu in RVP remains in the memory of those who experienced it. The recent earthquake of $2001 / 2002$ that destroyed schools, individual houses and some infrastructure drew a great deal of attention from different stakeholders (Pan African News Agency 2001; Mwamunyange et al. 2001).

More action needs to be taken to protect children when disasters strike (International Strategy for Disaster Reduction 2006). Pupils are at great risk when they have not been given proper knowledge on how to act before, during and after disastrous events. The October 2005 earthquake in Pakistan is a typical example, where over 17000 children died when their schools collapsed whilst they were attending classes (Wisner 2006). When children are well prepared to deal with such disasters they can save their lives and the lives of members of their community (Wisner 2006).

The end of the 20th century witnessed a paradigm shift from disaster relief to disaster risk management. In 1989 the United Nations General Assembly declared an International Decade for Natural Disaster Reduction. In ensuring that disaster risk reduction (DRR) is achieved, the World Conference for Disaster Reduction under the Hyogo Framework for Action set five priority actions (World Conference for Disaster Reduction 2005; Haulle 2007). These include, firstly, that DRR be given national and local priority, and secondly, that underlying disaster risk factors need to be reduced. The United Republic of Tanzania (URT) is a signatory to initiatives to establish proper institutions that focus on the prevailing global thrust in this regard. Tanzania's Disaster Relief Coordination Act No. 9 of 1990 that called for relief bases to be established was a response to global initiatives under the International Decade for Natural Disaster Reduction and United Nations Disaster Relief Organisation (URT 2002).

With the dawn of the 21st century, when the world experienced the shift to disaster risk management under the United Nations Office for Coordination of Humanitarian Affairs (UNOCHA) and International Strategy for Disaster Reduction (UNOCHA 2006), Tanzania developed and established a National Disaster Management Policy (2004) that began the 
mitigation and preparedness processes (URT 2004a). To link up with the DRR beginning at school, the country has embarked on two comprehensive programmes, namely the Primary Education Development Plan and the Secondary Education Development Plan, which guide curricula, human resource development, and school building design and management.

Tanzania aims at improving primary and secondary education and increasing enrolment coupled with rapid construction of schools in order to improve the education status of the community as a whole (URT 2004b). Effective planning of development of the school projects seeks to offset the vulnerability of the on-site conditions and underlying societal factors (Wisner et al. 2005). In this regard, schools play a great role as learning institutions, both in instilling cultural values and in passing on traditional and modernday knowledge systems to younger generations.

On the one hand, protecting children from natural disasters requires two distinct and yet inseparable priorities for action, namely disaster risk education and school safety (International Strategy for Disaster Reduction 2006). On the other hand, when well prepared pupils may cause a significant trickledown effect and save the lives of many in their communities as they act as a bridge between theory and practices (United Nations Children's Fund 2007). Children have been a significant base for development. Schools as learning centres bring a large number of children together and thus require safer environments for learning. However, such centres have often been located in earthquake-fragile environments, and sometimes the poor design of school structures intensifies levels of vulnerability and risk from disaster (United Nations Children's Fund 2007).

By the same token, poor involvement on the part of the stakeholders and the low level of community awareness of management of natural disasters might lead to severe adverse short- and long-term impacts on schools and the community as a whole. RVP has frequently experienced earthquake disasters. Tectonic earthquakes recur and it is difficult to predict their occurrence. Therefore, there is a need to identify the coping mechanisms employed in locating and designing schools, and to increase community awareness in reducing the risk from earthquake disasters. Through time schools have been centres for instilling knowledge, culture and values. The main objective of the study was to evaluate coping mechanisms employed by the local communities and society to reduce earthquake disaster risks in schools in RVP.

\section{Description of study area}

The study was carried out in RVP in the Great East Africa Rift Valley System. Geographically the study area extends from $33^{\circ} 10^{\circ} \mathrm{E}-33^{\circ} 58^{\circ} \mathrm{E}$ and $06^{\circ} 40^{\circ} \mathrm{S}-07^{\circ} 36^{\circ} \mathrm{S}$ (URT 1957). Administratively, the area is located in Rungwe District, one of the eight districts of Mbeya region in south-west Tanzania, East Africa. It is bordered to the north by Mbeya Rural District, to the east by Iringa region, to the south-east by Kyela District, south-west by Ileje District and west by Mbeya Urban District (Figure 1).

Rungwe District is divided into 30 wards. RVP lies between the eastern and western arms of the Great East Africa Rift Valley System at between $500 \mathrm{~m}$ and $2960 \mathrm{~m}$ above mean sea level, the highest point being Rungwe Mountain.

The district is characterised by steep slopes, plateaux and mountainous relief, common features of areas dissected by the Rift Valley (URT 1960). Mountain systems include the Livingstone, Kipengere and Uporoto ranges, whilst the main plateau in RVP is Mwakaleli Valley. It is also characterised by volcanic activities that involve the presence of hot springs, namely Kalambo Kajala, Nanyara and Moffate in Kyejo, Isebe and Shiwaga. After the main volcanic cones of Kiejo and Rungwe built up, a period of explosive activity in the RVP gave rise to numerous explosive craters, some of which now hold lakes such as Ngozi, Masoko, Itende, Itamba, Ilamba, Kingiri, Ikapu, Chungururu and Nzumbwe (URT 1960).

Rungwe District is drained by a number of rivers, major ones being Kiwira, Mbaka and Rufiryo, whilst others are Mwalisi, Kasefuka, Kakumbulu Mwina Sangaje and Nkuka. The district has a great reserve of forest around Rungwe Mountain and the Livingstone and Kipengere ranges. The vegetation cover includes bamboo trees, miombo woodlands and savannah. RVP is cool with temperatures ranging from $0{ }^{\circ} \mathrm{C}$ to $20^{\circ} \mathrm{C}$, and experiences heavy rain totalling about 2500 mm per year (Rugumamu 1988).

The area is densely populated due to its fertile soil and the favourable climatic conditions that support a wide variety of crops (Rugumamu 1988). Such crops include potatoes, maize, rice, bananas and beans and cash crops such as tea, coffee and cocoa. High production of these crops attracts people to settle in the area. Agriculture is the major economic base of the livelihoods of RVP residents. The district covers $2211 \mathrm{~km}^{2}$ and its population density is 139 people per $\mathrm{km}^{2}$. About onethird of its population is made up of pupils in secondary and primary education. More than 80000 pupils are in primary schools.

\section{Sampling and data collection techniques}

Multi-stage sampling was used to obtain 75 pupils from six schools (at least 10 pupils from each school) in the RVP for interviews using a semi-structured questionnaire. In addition, multi-stage sampling was used to contact 62 heads of households in four villages in the area for interviewguided questionnaires. Further sampling included 31 people in focus group discussions (FGDs), these including teachers, education officials, District Disaster Management Committee and Regional Disaster Management Committee members, and those involved in non-governmental organisations and other development work. Public hearings were held for 120 pupils and 101 villagers in the selected schools and villages. 
Itagata, Busona, Isange, Ndala, Mbafwa and Lutengano schools were involved in the study (Figure 3).

A semi-structured questionnaire was employed for individual students and heads of households, and elicited both qualitative and quantitative information (Creswell \& Clark 2011). The location, design and types of structures and materials used in construction of houses were assessed. A geographical positioning system was used to locate the schools that were later linked to a geological map. FGDs were employed to obtain specific knowledge on earthquakes and coping mechanisms from teachers, religious leaders, local leaders, retired officers and development actors. The latter method was used to fill the gaps left by the other techniques used.

\section{Results and discussion}

This section presents analyses and discusses disaster risk management in the study area. It analyses and discusses levels of community awareness of earthquake disaster and coping mechanisms pertaining to the disaster.

\section{Community awareness on earthquake disaster}

The RVP community has lived side by side with earthquake risks for a long time, to the extent that they know the phenomenon and how to adjust themselves before, during and after an emergency. The community's awareness was evaluated by their ability to identify the events' local names, expressing information on their causes and related activities for DRR. The local people were able to identify the quakes

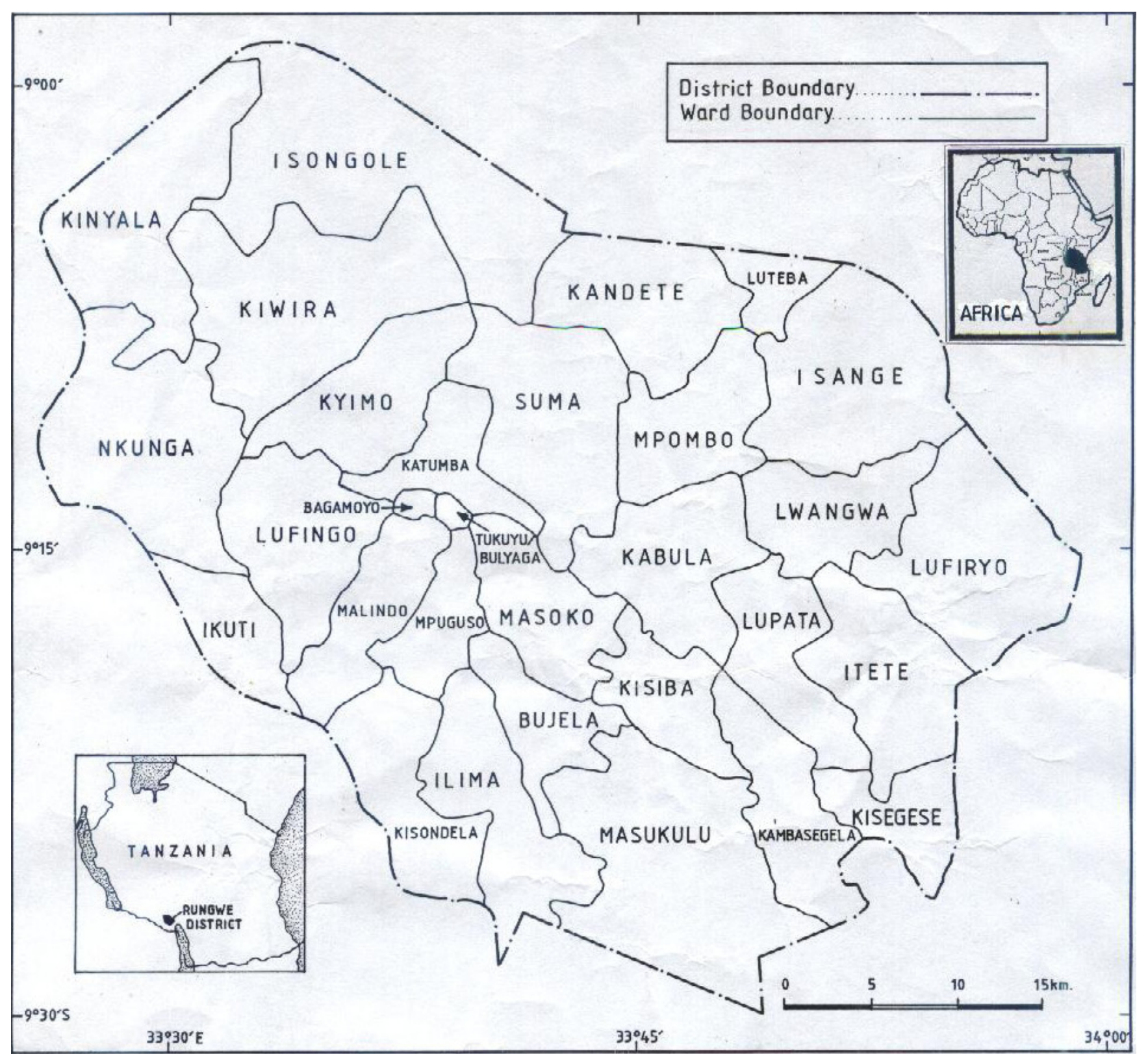

Source: United Republic of Tanzania (1957, 1960, 2004c)

FIGURE 1: Map of Rungwe District showing location and division of wards. 
by their tribal language as 'Kasenyenda'. They also identified them as being caused by volcanic eruption, plate tectonic movement, gas exploitation and explosions (Table 1). The communities were also aware of fragile environmental features such as steep slopes and valley bottom settlements that could easily affect their livelihoods in times of tremors.

The findings of the current study are in agreement with those of Haulle (2007), who also observed that the local people are familiar with the problems they are facing. It was found that some of the causes identified by respondents (both heads of households and pupils) were non-scientific and most likely arose from local beliefs. Such causes included myths about snakes, climatic conditions, gas explosions, and other events. However, those causes provide a base for scientific inquiry and reflect the relationships that might exist between earth components such as geological, atmospheric and human systems. For instance, Datta (2002) noted that beliefs and taboos were key in the search for causes of an earthquake since, for example, Aristotle believed that gas beneath the Earth's surface caused earth tremors.

Furthermore, the study found that there was a strong relationship between precipitation and tremors; tremors were said to be intense and recurrent in the rainy season in the RVP. The earthquakes of 2000/2001 and December 2009 were cited as evidence. These findings are similar to those of Datta (2002) and Haulle (2007), who found that most tremors are experienced during rainy seasons. There is no scientific explanation for this relationship, but it forms a basis for scientific inquiry and community adjustment.

The study revealed that the communities have a belief in 'Nyifwila', a gigantic and mythical snake that moves beneath the crust in defined locations. The snake is believed to have multiple heads, which are located in different hilltops. According to geological maps (URT 1957), the so-called Nyifwila path along the Mbaka River was shown to be the actual fault line with active displacement. The myth of the snake in this situation therefore makes some sense and is useful for DRR. The residents of RVP had a history of behaviour of leaving such an environment in order not to disturb or interfere with Nyifwila. Such a myth can also be a part of security, as long as the taboo saves lives. As one of the respondents stated:

\footnotetext{
'The big problem with you experts is to think nothing good can come from we uneducated people. When we tell you this zone is dangerous you want scientific proofs. We don't have them only we know that the area is dangerous and we have been able to survive. You are required to find the sense of our knowledge. Unfortunately you end up despising us, but we believe and live to tell the tale of disasters'. (Elder, Itagata village)
}

According to the URT (2004a), the media have to play a major role in DRR. However, in practice the study revealed that the community is informed through their own experiences and practices. The main source of community awareness was either education and training (45\% of respondents) or observation and verbal communication (44\%). It appeared that only one workshop organised by the University of

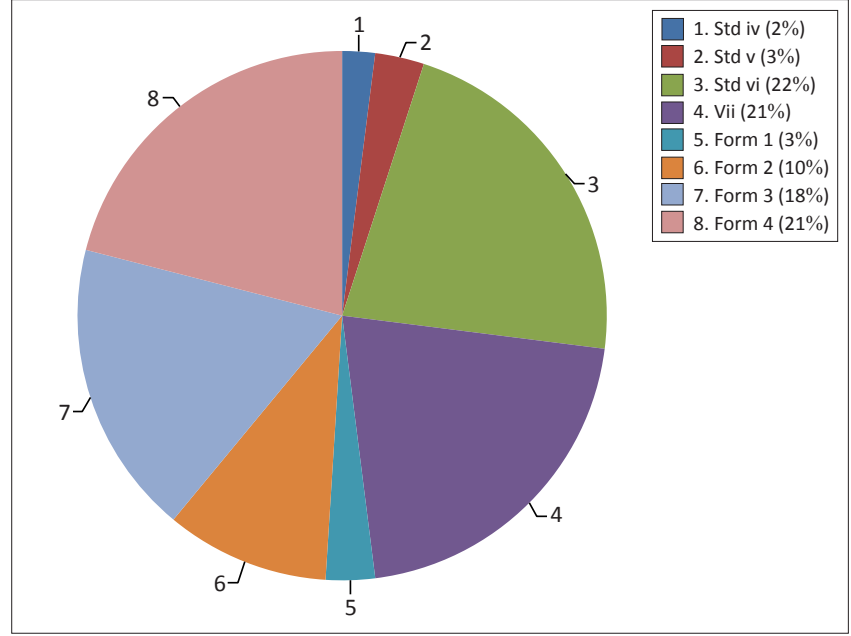

Source: Field survey 2009

FIGURE 2: Level of awareness of earthquake disaster among pupils.

TABLE 1: Responses on causes of earthquake from pupils and heads of households.

\begin{tabular}{lcc}
\hline Cause of earthquake & \multicolumn{2}{c}{ Respondents $(\mathbf{\%})$} \\
\cline { 2 - 3 } & $\begin{array}{c}\text { Pupils } \\
(\boldsymbol{n}=\mathbf{7 5})\end{array}$ & $\begin{array}{c}\text { Heads of households } \\
(\boldsymbol{n}=\mathbf{6 2})\end{array}$ \\
\hline Volcanic eruption & 39.3 & 19.5 \\
Tectonic plates collision & 15.5 & 7.3 \\
Gas explosion & 3.6 & 9.8 \\
Gas exploitation & 9.5 & 12.2 \\
Mining activities & 2.5 & 2.4 \\
Myth of snake & 9.5 & 12.2 \\
Climatic condition & 7.1 & 12.2 \\
Other† & 2.4 & 4.9 \\
Not aware & 13.1 & 19.5 \\
\hline
\end{tabular}

Source: Field survey 2009

$\dagger$, This includes factors such as God's anger or will, overstocking and deforestation.

Dar es Salaam has been conducted in Rungwe involving local government officials. In relation to verbal communications, the study revealed that elders and those people who experienced the tremors passed the stories on to those who did not experience them. This is similar to the observation in Ludewa District, where most respondents became aware through observation and hearing, since they were not able to access newspapers, nor was radio available throughout the entire district (Haulle 2007).

Tanzania has signed and ratified the Hyogo Framework for Action 2005-2015 (World Conference for Disaster Reduction 2005), yet as explained above its objectives were not realised at grassroots level during its period of review (2005-2010). For instance, DRR should be given national and local priority. Community participation in DRR seems not to be considered significant, as teachers, pupils and local communities were not aware of the policies related to DRR as proposed by the disaster management policy. This finding is also supported by Haulle (2007) with regard to the Ludewa District, where the communities were similarly unaware of policies and institutions relating to DRR.

This study noted that traditional knowledge of DRR is indeed available amongst teachers, pupils, heads of households and 
leaders. Such knowledge was not embedded in curricula and was viewed as barbaric, whilst the modern technologies were limited to only a few in the study area. The curricula indicate causes of earthquake (URT 2006), yet they do not examine factors that might cause a disaster and how people can prepare themselves for disasters. The syllabi covered types, causes and effects (URT 2006), which is less significant than what is required to make societies resilient during disasters.

People need to be aware of the causes, impacts and how the hazard is translated into disaster (Wisner et al. 2005). The syllabus shows that the earthquake is taught about in Standard V and Form III (URT 1997; URT 2006). The study revealed that Standard Vl and VII and Form 111 and IV respondents were more aware than other classes (Figure 2), because they had already been taught about earthquakes. It appears that these classes are about to sit for national examinations, which therefore implies that the instilled knowledge is intended for passing examinations and not for life - and explains why pupils in Standard V and Forms I and II were not knowledgeable on the matter. Further, it was noted that DRR was not mainstreamed in school curricula.

Before establishing an education system, a society should answer the question as to what kind of society they are trying to build (Nyerere 1967). Only when the society is clear about the kind of society they are trying to build can they design their educational services to serve their goals and hence attain development. In this case, if the community is aware that it needs to build its resilience, then the system of education could be devised to suit the purpose. Sustainable development means sustainable DRR.
The situation should be viewed in the light of the FGDs' contention that there is no need to mainstream DRR in school curricula because a lot of issues have been mainstreamed and so the syllabus is overloaded. The statement made sense, because when the curricula were reviewed it was seen that extra issues had been added to the extent that the syllabi could not be covered in the period allocated, nor bring about the hoped for changes for the pupils. It appears that the syllabi were overloaded and thus needed revision in order to accommodate all that is required for community resilience and development.

The syllabi are overloaded because the curriculum has been changed four times in the past 15 years. The study revealed that changes of the Minister of Education led to changes in the curriculum, but this was not related to change in the national education policy - each of the two was reviewed separately. For instance, a review of education policy is in progress, whilst the curriculum of teachers' training was reviewed last year. In some cases the change of curriculum involved replacing a curriculum denounced by the previous Minister of Education. So far issues like entrepreneurship, gender, environment, information technology, French, vocational skills, personality and sports have been mainstreamed, whilst corruption, human rights and DRR are on their way to being mainstreamed.

The situation, however, justifies the finding that the question of the education system has not yet been answered properly. This study revealed that pupils who were about to sit the national examinations were more aware than any other

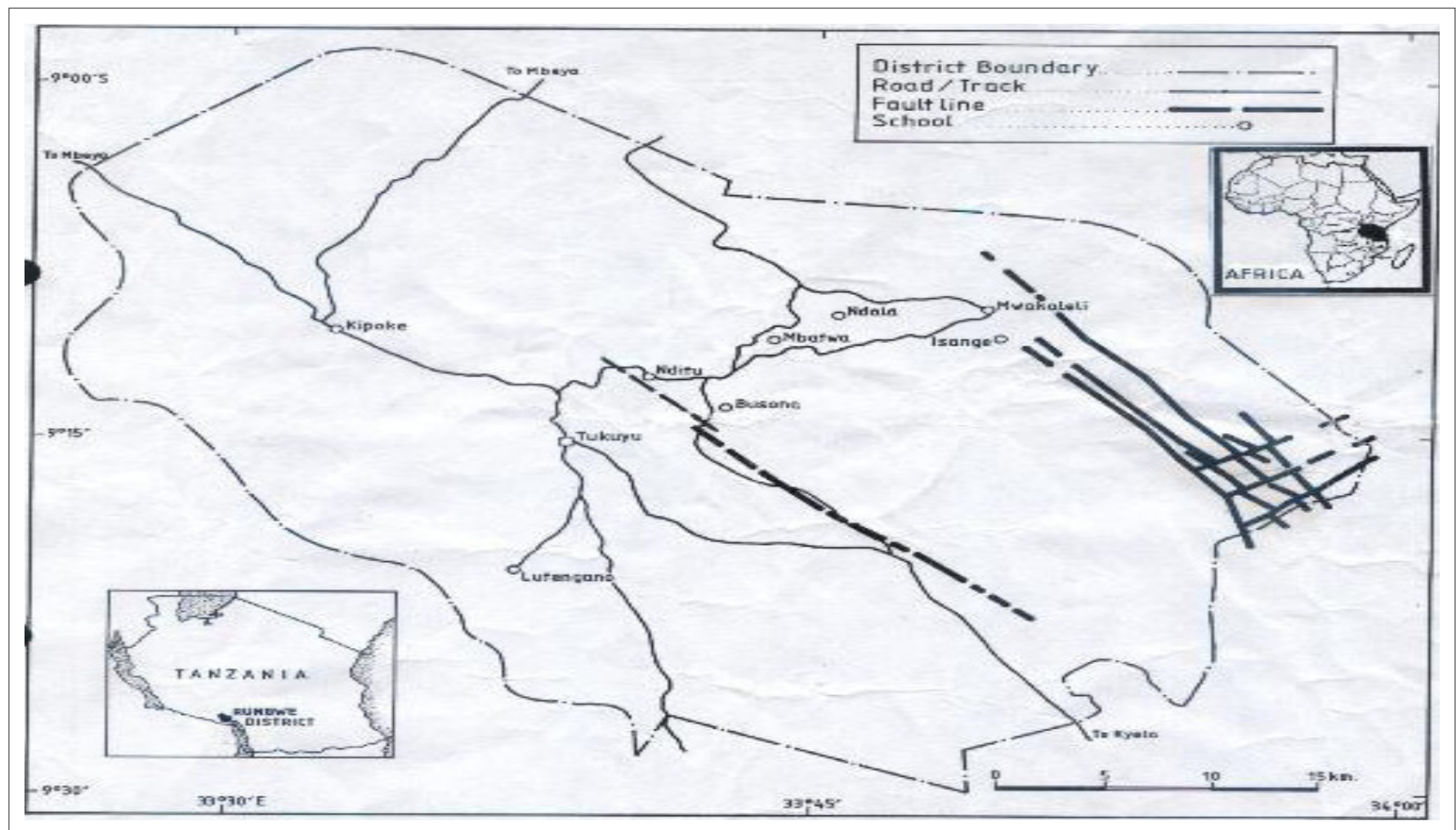

Source: United Republic of Tanzania (1957, 1960, 2004c)

FIGURE 3: Map of Rungwe District showing major fault lines and areas included in the study. 
classes, even though what was asked was taught in the previous education level. This is also reflected in the finding that knowledge is taught for passing the exams and not for development. The education system has the power to provide a way towards development by creating opportunities for students to improve their income and understanding and to rise above the persistent vulnerability level (Wisner et al. 2005; Rugumamu 2000). Education is a tool for those who can assume a better role in the event of impending disaster or if a disaster actually strikes, enabling development of rational decisions. With regard to this view, the community cannot be able to decide rationally in the absence of a proper education system - hence the objectives of the Hyogo Framework cannot be achieved.

The FGDs with teachers revealed that they were neither involved in review of the curricula nor in development plans - they were the receivers of ideas.

\section{Management cycle and coping mechanisms}

Mitigation measures are key elements in sustainable development and DRR. They include spatial planning, design of infrastructure, the legal framework and regulations (URT 2004a).

The findings showed that spatial or land use planning was not done properly since the valley bottom and slopes were observed to be most densely settled. It was also found that no building codes were adopted for such a fragile environment.

In relation to design of buildings, bamboo-pole houses are considered to be able to withstand tremors (Rugumamu, Hambati \& Haulle 2009). However, the housing policy insists on brick houses whilst discouraging the bamboo-pole houses as they are considered to be weak structures despite scientific research that proves their durability (International Network for Bamboo and Rattan 2009; Carney 2011). People are placed in the dilemma of whether to build a brick or a bamboo house as there is policy conflict on the standards of good housing. If the conflict persists, earthquake disasters will continue to impact the community. The construction of school buildings, however, does not take into account the impact of quakes (URT 2004b). Wooden classrooms in Mbafwa were attractive and stable for DRR, yet there has been no replication of such structures.

The Primary and Secondary Education Programmes have overlooked the aspect of tremors, which is important in terms of building location and design. Schools such as those at Busona, Mbafwa and Ndala were located on the fault line and in zones of intensive shears, and were thus highly impacted (see Figure 2). Pupils are occupying vulnerable buildings both at school and at home. This is the result of a top-down approach to decision making (Thapa 2002; Haulle 2007); the study revealed that the community members were just recipients of inventions and impositions. There is no active participation of stakeholders in planning and implementation of development projects. The adopted bamboo-pole housing technology from China is not compatible with the environment in RVP, as bamboo houses are costly. The cost of such two-roomed houses was estimated to be 10 million Tanzanian Shillings (approximately US \$7.150), whilst their durability is more than 100 years. Those that are wooden cost four to five million Tanzanian Shillings. The technology adopted includes treatment of bamboo and use of wire mesh and cement to strengthen the walls, which makes them expensive. Bamboo is plentiful and easily available in the study area.

No clear early-warning system exists in RVP, and most of the people are caught unawares by earthquakes. However, a few of the respondents had learnt that when 'mipafwa' (a tree that flowers occasionally) bloomed, it implied that tremors were likely to occur, and they got prepared and communicated the information to those close to them. Mobilisation of resources is also important for addressing the post-disaster phase (URT 2004a). Rungwe District has neither funds nor even a bank account for such mobilisation - the bank account was closed after the rehabilitation phase of the 2000/2001 episode. This implies that in a time of emergency the rescue and relief will be difficult to fund because of poor preparedness.

According to the Hyogo Framework for Action priority is to be given to the mitigation and preparedness phase (World Conference for Disaster Reduction 2005); however, the reality is that coping mechanisms in the pre-disaster phase are very weak and underdeveloped. The post-disaster phase is also unorganised. Some of the institutions in place are not in harmony. During the 2000/2001 disaster there was a problem with distribution of resources to people in need. It was found that nepotism affected relief services so badly that some institutions withdrew. For instance, the study found out that due to these problems Caritas Tanzania stopped the reconstruction of wooden houses and their participation in the bamboo houses pilot project.

Although the end of the 20th century witnessed a paradigm shift from disaster relief to emergency management, the approaches are still focusing on rescue, relief, rehabilitation and reconstruction, which are also improperly handled (Rugumamu et al. 2009). Disaster mitigation and preparedness appeared to be just ad hoc.

\section{Conclusions and recommendations}

It was found that the culture of DRR in Rungwe District was not well developed; thus drastic measures are needed to impart this to the society. RVP communities are relying heavily on traditional technologies rather than modern technologies for their survival. Whilst availability and accessibility of the latter is limited, the traditional technologies available are not sufficient to make the community resilient to risk of disaster. In relation to awareness, the study noted that the local community was aware of the possibility of quakes, but little attention was paid to architectural design and building location. 
The resilience of the school community is questionable because the curriculum is not stable due to several recent changes, including mainstreaming of different issues over a short period of time without great attention to DRR. This situation limits the probability of saving the lives of the children themselves and of the community at large. On the other hand, activities before, during and after disasters were the result of normal practices, panic and accidental actions respectively. Local coping mechanisms such as forecasting of tremors, land use allocation and bamboo-made houses were not accessed by many. Although expensive in relation to their level of income, the wooden and bamboo housing had the capacity to withstand tremors. Structural designs adopted conflicted with policies and regulations against deforestation and standards of good housing.

On the basis of these findings, it is therefore recommended that DRR be given high priority by the government, through making Disaster Management Committees operational before and after the disaster. It is an urgent necessity to involve and coordinate other stakeholders in order to reduce conflict and enhance impartiality.

It is imperative to initiate debate on the system of education needed in Tanzania that will address the needs of the society, and to find proper curricula to meet those needs and integrate DRR; the curricula must be practical and not examination oriented.

It is also recommended that architectural designs need to consider on-site conditions and the resources available after hazard and vulnerability mapping. It is therefore recommended that a study for mapping environmental hazards and risk analysis in zoning areas be carried out in the study area. In addition, it is recommended that further studies be conducted for the identification, analysis and integration of proven traditional knowledge systems for DRR into school curricula and enhancement of knowledge instilled into pupils that is pertinent to DRR and their life.

\section{Acknowledgements}

I am grateful to the ProVention Consortium for funding the study and Professor William Rugumamu for mentoring me. I am also grateful to Enock Makupa and Edista Abdala for their assistance in data collection. I am also thankful to Waziri Mwakibolwa and Ubaya Msemwa for their moral and material support.

\section{Competing Interest}

The author declares that he has no financial or personal relationship(s) which may have inappropriately influenced him in writing this article.

\section{References}

Carney, E., 2011, 'Bamboo and the Environment', in Green Earth News, viewed 25 September 2011, from http://blog.greenearthbamboo.com/20110826/ bamboo-the-environment/earthquake-proof-bamboo-homes/

Creswell, J. W. \& Clark, V. P., 2011, Designing and Conducting Mixed Methods Research, Sage Publications, London, p. 457.

Datta, A.K., 2002, Introduction to Physical Geology, Kalyani Publishers, New Delhi, p. 230.

Haulle, E., 2007, 'The Role of Traditional Environmental Knowledge Systems in the Earthquake Disaster Management in Ludewa District', MA Dissertation, Department of Geography, University of Dar es Salaam, Tanzania.

International Network for Bamboo and Rattan, 2009, Global Bamboo Housing Programme, viewed 25 September 2011, from http://www.inbar.int/Board. asp?Boardid $=67$

International Strategy for Disaster Reduction, 2006, 2006-2007 World Disaster Reduction Campaign: Disaster risk reduction begins at school, viewed 26 June 2007, from http://www.unisdr.org/eng/public_aware/world_camp/2006-2007/ 2007, from http://www.unisdr.org/eng/public
pdf/WDRC-2006-2007-English-fullversion.pdf

Nyerere, J.K., 1967, Education for Self-Reliance, Ministry of Information and Tourism, Dar es Salaam, Tanzania, p. 28

Pan African News Agency, 2001, 'Tanzania quake victims get relief', viewed 15 June 2007, from http://reliefweb.int/node/74576

Rugumamu, W., 1988, 'Soil Resource Survey and Evaluation for Agricultural Land Use Planning in Parts of Mbeya Region', D.Phil. thesis, Department of Geography, University of Dar es Salaam, Tanzania.

Rugumamu, W., 2000, 'Managing Environmental Disaster: A search for an Institutional Framework for Tanzania', Journal of the Geographical Association of Tanzania 29, 79-92.

Rugumamu, W., Hambati, H. \& Haulle, E., 2009, 'Building community resilience to earthquake disaster risk reduction in Sub-Saharan Africa: A case of Southwestern Tanzania', in W. Rugumamu \& J.R. Ikingura (eds.), Launching of Internationa Year of Planet Earth on African Region organised by Tanzania UNESCO National Committee, pp. 114-128, Tanzania UNESCO National Committee, Arusha, Tanzania.

Thapa, M.B., 2002, 'Disaster to Development: The Case of Community-led Disaster Management in Nepal', paper presented at the United Nations Development Programme Regional Workshop on Total Disaster Risk Management, Kobe, Japan, 7-9 August.

Mwamunyange, J., Mande, M. \& Mpinga, J., 'Tremors leave 1,000 Families Homeless', The East African, 18 January 2001, viewed 22 September 2011, from http:// allafrica.com/stories/200101180379.htm

United Republic of Tanzania, 1957, Geological Survey of Tanzania; Tukuyu Quarter Degree sheet No. 559, Geological Survey Department, N.E. Dodoma.

United Republic of Tanzania, 1960, 'Rungwe Volcanics at the Northern End of Lake Nyasa', p. 172, in Geological Survey of Tanganyika, URT, Dar es Salaam.

United Republic of Tanzania, 1997, Geography Syllabus for Secondary Schools Form I-VI, Ministry of Education and Culture, Dar es Salaam.

United Republic of Tanzania, 2002, National Disaster Relief Coordination Act No. 9 of 1990, Parliament of United Republic of Tanzania, Dar es Salaam.

United Republic of Tanzania, 2004a, National Disaster Management Policy, Prime Minister's Office, Dar es Salaam.

United Republic of Tanzania, 2004b, 'Secondary Education Development Plan (SEDEP) 2004-2009', Ministry of Education and Culture, Dar es Salaam.

United Republic of Tanzania, 2004c, 2002 Population and Housing Census vol. IV, District Profile Rungwe, National Bureau of Statistics, Dar es Salaam.

United Republic of Tanzania, 2006, Geography Syllabus for Primary schools standard III-VII, Ministry of Education and Vocational Training, Dar es Salaam, p. 94.

United Nations Children's Fund, 2007, Promoting 'Earthquake Safer Schools', Saving Lives, viewed 15 June 2009, from http://www.unicef.org/armenia/media_6268. html

United Nations Office for the Coordination of Humanitarian Affairs, 2006, The International Decade for Natural Disaster Reduction, (IDNDR) (1990s), viewed 15 June 2009, from http://www1.cira.corostate.edu/ramm/hillger/IDNDR.htm

World Conference for Disaster Reduction, 2005, Hyogo Framework for Action 2005-2015: Building the Resilience of the Nations and Communities to Disasters - Notes of the conference, Kobe, Hyogo, Japan, 18-22 January, viewed 06 May 2009, from http://www.unisdr.org/wcdr/

Wisner, B., 2006, Let Our Children Teach Us: A Review of Education and Knowledge in Disaster Risk Reduction, Books For Change, Bangalore, p. 135.

Wisner, B., Blaikie, P., Cannon, T. \& Davis, I., 2005, At Risk: Natural hazards, people's vulnerability and disasters, Routledge, London, p. 276. 